\title{
Health care retail clinics: current perspectives
}

\author{
This article was published in the following Dove Press journal: \\ Innovation and Entrepreneurship in Health \\ 31 March 2016 \\ Number of times this article has been viewed
}

\section{Amer Kaissi \\ Department of Health Care Administration, Trinity University, San Antonio, TX, USA}

Correspondence: Amer Kaissi Department of Health Care Administration, Trinity University, I Trinity $\mathrm{PI}$, San Antonio, TX 782 I2, USA Tel +l 2109998132

Email amer.kaissi@trinity.edu
Abstract: Retail clinics represent a major innovation with a radical value proposition in American health care: convenient locations and hours, walk-in care, short waiting times, and transparent pricing. Many organizations, groups, associations, and individual providers affect and are affected by retail clinics. The main winners from the retail clinic trend are insurance companies and third-party payers, nonphysician providers, employers, and patients. The main losers are primary care physicians and medical group practices, and possibly emergency departments and urgent care clinics. Hospital systems are either potential winners or losers, depending on their ability to collaborate with, become subcontractors for, and extend services of retail clinics. Research evidence suggests that retail clinics represent a low-cost, high-quality, and convenient alternative to traditional primary care physician offices and hospital emergency rooms. Given their recent growth and strategies of directly addressing problems surrounding care convenience, they constitute a form of innovation in health care. However, they do not seem to follow the traditional path of disruptive innovations displacing sustaining ones. Rather, due to legislative and other factors, retail clinics are now being adopted by traditional organizations such as hospital systems. In the last few years, there have been many signs that clinic operators are seeking to change the model by expanding the scope of services offered into chronic disease management. It is not clear whether these strategies are sustainable.

Keywords: retail clinics, hospitals, quality, convenience, patient satisfaction, disruptive innovation

\section{Introduction}

Retail clinics represent a major innovation with a radical value proposition in American health care: convenient locations and hours, walk-in care, short waiting times, and transparent pricing. Originally limited to a few stores, they have recently evolved into a common feature of a health care system transformed by increasing consumerism, provider shortages, and reform pressures. In this paper, we review the retail clinic trend since its inception, and consider the role that the clinics will play in the health care system in the near and long-term future.

\section{Background}

The first retail clinic appeared in 2000 at a grocery store in the state of Minnesota and was operated by QuickMedx. The clinic was small in size, treated minor common medical conditions, operated on a cash-only basis, and did not accept insurance at first. ${ }^{1-3}$ As QuickMedx grew, it changed its name to MinuteClinic, and was later acquired by the retail pharmacy chain CVS. ${ }^{3}$ Meanwhile, other retail clinic companies such as the Little Clinic and the Clinic at Target started to form. 
The clinics grew at a slim rate between 2000 and 2003, with faster, yet modest growth in the following 3 years. ${ }^{4,5} \mathrm{In}$ 2006, 152 new clinics opened, making it the year when retail clinics finally took off as a new business model. This was followed by 2 years of exponential growth with 554 and 426 new clinics in 2007 and 2008, respectively. However, coinciding with the economic recession, the following 2 years (2009 and 2010) witnessed stagnation, as the number of clinics opening barely surpassed the number of clinics closing. Another wave of gradual growth started in 2011 and continues till today. The current number of retail clinics stands at $\sim 1,900$ nationwide. ${ }^{6}$ This growth in numbers has been complemented by a growth in usage rates. In a recent survey of health care consumers, $23 \%$ of the respondents indicated that they or someone in their household have sought treatment at a retail clinic. ${ }^{7}$ The clinics operate in 43 states and are mainly located in urban and suburban areas with populations having higher household incomes and better education. ${ }^{8}$

A retail clinic nowadays occupies 400-600 square feet and typically consists of a small reception desk or kiosk for registration, a waiting area, one or two exam rooms, a lab area, and a restroom. In large grocery stores, clinics tend to be located in prime spots such as the front of the store next to the main cash registers, whereas in retail pharmacies, they are typically located in the back of the store in close proximity to the pharmacy. The clinics are primarily staffed by nurse practitioners and physician assistants. These nonphysician providers are usually supervised by an off-site physician who is available by phone for consultation. The physician acts as the medical director of the clinic, where he/she provides quality oversight through periodic review of medical charts of patients seen in the clinic. ${ }^{9-11}$

One of the main distinguishing features of retail clinics is the provision of a menu-style pricing system that is displayed in most sites and on the operators' websites. For example, at CVS' MinuteClinic, prices of minor illness exams, minor injury exams, and skin condition exams range between $\$ 79$ and $\$ 99$. Screenings and physical exams and health condition monitoring range between $\$ 59$ and $\$ 109$, whereas vaccinations range between $\$ 31.99$ and $\$ 234.99 .{ }^{3}$ Patients with insurance coverage have a co-pay that is similar to or less than their primary care physician co-pay, depending on their individual plan. ${ }^{12}$ By design, retail clinics have a very limited scope of practice. Approximately $90 \%$ of the visits are for ten simple acute conditions and preventative care: upper respiratory infections, sinusitis, bronchitis, pharyngitis, immunizations, otitis media, otitis externa, conjunctivitis, urinary tract infections, and screening lab test or blood pressure check. ${ }^{13}$
These conditions account for only $18 \%$ of all primary care physician office visits and $12 \%$ of all emergency room visits. An interesting recent development is an increase in patients receiving vaccinations and other preventative services in retail clinics, which hints that retail clinics may be playing an increasingly important public health role in the communities in which they operate. ${ }^{14}$

Retail clinic operators and industry experts agree that the retail clinic business model is extremely challenging. To operate efficiently, the clinics needs to see $\sim 30$ patients per provider per day, which is rarely attainable outside of winter/ flu season. But it is important to note that from the retailers' perspective, the clinics can bring in indirect revenue that goes beyond what patients spend in the clinic or what their insurance claims amount to. Most clinics are located in stores that have an on-site pharmacy. ${ }^{5}$ Therefore, retailers hope that while customers are in the store to be seen at the clinic, they might fill their prescriptions at the store's pharmacy, purchase over-the-counter medications, or otherwise buy miscellaneous items from the store, thus "expanding their basket". ${ }^{9}$ For example, $70 \%$ of MinuteClinic's patients become new pharmacy visits, $38 \%$ buy an over-the-counter product, and $80 \%$ buy general items from the store during their visit. ${ }^{15}$

One of the basic convenience premises for retail clinics is their availability after hours on weekday evenings and weekends, when primary care physician offices are typically closed for business. For these offices, $93 \%$ of visits occur during the weekday peak hours (between 8 am and $6 \mathrm{pm}$ ), while only $4 \%$ of visits occur during weekday off-peak hours (after $6 \mathrm{pm}$ ) and only $3 \%$ occur on weekends. ${ }^{16}$ In contrast, $58 \%$ of retail clinic visits occur during the weekday peak hours, $26 \%$ occur on weekends, and $16 \%$ occur during weekday off-peak hours. Retail clinics are open an average of 11 hours during weekdays, 8.5 hours on Saturdays, and 7 hours on Sundays. ${ }^{5}$ This implies that retail clinic providers are acting as important extenders for physician practices and are providing an alternative to expensive settings such as emergency rooms and, to a lesser extent, urgent care centers for the treatment of minor conditions.

Another major convenience factor of retail clinics is the walk-in aspect and the short wait times. Some clinics use pagers, such as those used in restaurants, to alert patients that a provider is available, which allows the patient to wander around the store instead of waiting in the clinic itself. ${ }^{17}$ Evidence suggests that $21 \%$ of retail clinic patients are seen immediately and $54 \%$ wait $<15$ minutes. ${ }^{18}$ The total visit duration for a retail clinic from check-in to check-out is 32 minutes, compared to 81.9 minutes at a physician office. ${ }^{16}$ 


\section{Major stakeholders}

Many organizations, groups, associations, and individual providers affect and are affected by retail clinics. The main winners from the retail clinic trend are insurance companies and third-party payers, nonphysician providers, employers, and patients. The main losers are primary care physicians and medical group practices, and possibly emergency departments and urgent care clinics. Hospital systems are either potential winners or losers, depending on their ability to collaborate with, become subcontractors for, and extend services of retail clinics. ${ }^{19,20}$ In this section, we assess the position of various stakeholders and review the research and evidence pertaining to their relationships with retail clinics.

\section{Consumers and patients}

Retail clinic consumers tend be in the 18-44 years age group, whereas patients in other age groups are more likely to visit primary care physicians and hospital emergency rooms. ${ }^{13}$ Similarly, younger families (age 18-34 years) are more than twice as likely as older families (age 50-64 years) to use a retail clinic. ${ }^{21}$ However, families with children are more likely to use retail clinics than single adults or couples, thus suggesting that consumers are starting to use retail clinics for their children's acute care needs. ${ }^{21}$

Retail clinic users are less likely to have a primary care physician than the general population. Approximately $60 \%$ of patients visiting the clinics have no primary care physician relationship, compared to only $20 \%$ in the general population. ${ }^{13}$ Moreover, families with no usual source of medical care are more likely to use retail clinics than the families with a usual source of care. ${ }^{21}$ Approximately one-third of retail clinic patients would not seek any care if the clinic was not present. ${ }^{22}$ Consumers' reasons for visiting retail clinics tend to focus on convenience, availability, and short wait times. Recent surveys have found that the main reasons for visiting a retail clinic versus other sites of care were "no need to make an appointment" (57\%), "acceptance of insurance" (46\%), "convenient location" (45\%), "less expensive" (42\%), "short wait times" (35\%), "open when the physician's office is closed" (34\%), "do not have a regular physician" (18\%), and "more pleasant experience than physician's office" $(9 \%){ }^{23}$

\section{Retailers and owners/operators}

The major retailers that have been involved in the retail clinic model are CVS, Walgreens, Walmart, Target, Kroger, H-E-B, Shopko, and Rite Aid, among others. ${ }^{5}$ MinuteClinic currently has the largest number of clinics with 901 clinics, followed by Walgreens Health Clinics with 437 clinics, Kroger Little Clinic with 140 clinics, and Walmart Retail Clinic with 103 clinics. ${ }^{24}$ When retail clinics first started to open, the main operators were investor-owned and venturebacked companies that were independent from the retailers. However, as the business model proved elusive and returnon-investments did not live up to potential, investors' patience ran out and they began to divest their stakes in some clinics. As a result, the proportion of investor-owned clinics fell, while the proportion of drug store owned clinics (such as CVS-owned MinuteClinic and Walgreens-owned Take Care) and hospital-owned clinics rose. Between 2007 and 2010, investor-owned retail clinics dwindled from $24 \%$ to $16 \%$, while hospital-owned clinics soared from $9 \%$ to $18 \%{ }^{25,26}$

The most prominent hospital systems that own retail clinics and operate them include the Mayo Clinic in Rochester, MN, Geisinger Health System in Danville, PA, and Sutter Health in Northern California. However, for the majority of hospital systems, outright ownership and operation of retail clinics are too costly and risky, and therefore, many have opted to partner/affiliate with retail pharmacy chains and other retail clinic chains. For example, CVS MinuteClinic has partnered with The Cleveland Clinic in Cleveland, the University of California-Los Angeles Health System in Los Angeles, Sharp Healthcare in San Diego, and Allina Health in Minneapolis/St Paul, among others. For hospital systems, retail clinics can provide relief for overcrowded emergency rooms, solution to primary care physician shortages, increase in referrals to physicians and hospitals, and possible increase in revenues. ${ }^{20,27-31}$ It is important to note that the dramatic increase in Electronic Health Record use as a result of the Health Information Technology for Economic and Clinical Health Act of 2009 has provided a new opportunity for collaboration between health systems and retail clinics. When a health system partners with or develops a retail clinic, a shared information system platform with the clinic allows the system to capture patients' clinical information and share it with its primary care physicians, specialists and administrators. If the patient requires additional services that are beyond the scope of practice of the retail clinic, he/she can be seamlessly referred to a primary care physician or specialty physician to be treated, or admitted to the hospital. But even if the patient does not need those services, having a shared Electronic Health Record permits the capture of that patient's data, especially if it is a "new patient" who has not used the system's services before. This data can be used for subsequent marketing and promotional efforts. 


\section{Emergency rooms and urgent care centers}

Retail clinics provide services for nonemergent, acute episodic illnesses, and can therefore represent a solution to emergency room overcrowding and overuse for minor illnesses. For example, insured patients with minor illnesses may elect to visit a retail clinic instead of an emergency room, at lower co-pays and much shorter waiting and examination times. In fact, many hospitals and health systems already have "fast-tracks" staffed by nurse practitioners and physician assistants to provide care for minor conditions in the emergency room. ${ }^{32}$ However, other less busy emergency rooms are not thrilled to be losing insured and paying patients to the retail clinics, with all the vanished revenue associated with these patients. ${ }^{20}$ Urgent care centers not only provide services that overlap with those of retail clinics, but also treat more serious illnesses and injuries, and are typically located in different settings such as strip malls. Therefore, retail clinics also pose a competitive threat to the viability of urgent care centers. ${ }^{32}$

\section{Physicians and physician groups}

To date, the fiercest opposition to retail clinics has come from primary care physicians such as family physicians, internal medicine physicians, especially pediatricians, and their professional associations. The main concerns raised by these provider groups have centered on quality of care, scope of practice, lack of coordination care, and overprescription of antibiotics and other medications. It is important to note that many of these concerns have proved to be unfounded, especially those related to quality of care, adherence to protocols, and coordination of care. Rigorous research studies have shown that quality of care in retail clinics is similar to, if not better than, the care provided in physician offices and other settings. Research also shows that providers strongly adhere to protocols, and that retail clinics, for the most part, do not disrupt the patient-physician relationship. Therefore, many analysts have suggested that physician concerns seem to be based on turf issues, possible loss of patients, and decreased revenues.

\section{Retail clinic outcomes}

Retail clinics represent a low-cost, high-quality, and convenient alternative to traditional primary care physician offices and hospital emergency rooms. In this section, we examine the evidence surrounding retail clinic quality and cost, and assess their effects on care coordination and patientphysician relationships.

\section{Quality of care}

In the early years, many patients perceived retail clinics as a lower-quality alternative to care provided in private physician offices. But recently, rigorous third-party research published in peer-reviewed journals has provided evidence about quality of care. Adherence to acute pharyngitis practice guideline in retail clinics compares extremely favorably with documented rates of adherence in primary care physician offices, which helps alleviate fears that retail clinics overprescribe antibiotics to boost sales in the in-store pharmacies. ${ }^{33}$ Similarly, no differences in the risk of early return visit (within 2 weeks) are found between retail clinic patients and physician office patients. For otitis media (ear infection), pharyngitis, and urinary tract infections, aggregate quality scores are similar at retail clinics $(63.6 \%)$, physician offices $(61.0 \%)$, and urgent care centers (62.6\%), but are lower for emergency rooms (55.1\%). ${ }^{13}$ More recent results suggest that retail clinics outperform ambulatory care facilities and emergency rooms on all quality measures for these same conditions. ${ }^{34}$ Antibiotic prescribing for acute respiratory infections in retail clinics is more diagnosis-appropriate than in primary care practices and emergency rooms. ${ }^{35}$ Therefore, there is strong evidence that for the minor conditions that they treat, retail clinic providers adhere strongly to clinical guidelines and strict standards, and provide high quality of care.

\section{Continuity of care and effect on primary care physicians}

A major criticism of retail clinics by physicians is that they lead to fragmentation of care and have a negative effect on the patient-primary care provider relationship. It is important to note that $61 \%$ of patients visiting a retail clinic do not have a primary care physician; therefore, for these patients, "there is no relationship to disrupt". ${ }^{13}$ As for the patients who do have a physician relationship, evidence suggests that they do not wish to replace their physician, but rather they use retail clinics as a back-up or alternative for minor health care needs. For more serious issues or chronic illnesses, they continue to seek care from their physician. ${ }^{22}$

More recent studies have provided some mixed evidence on the issue. For example, visiting a retail clinic instead of a primary care physician is associated with a decrease in subsequent continuity of care. However, there is no difference among patients who visit a retail clinic versus a primary care physician in terms of receipt of preventative health examinations such as screening for breast cancer, cervical cancer, colorectal cancer, or Chlamydia, or receipt of diabetes management such as hemoglobin A1c testing, 
eye examinations, low-density lipoprotein testing, and nephropathy care. ${ }^{36}$ Similarly, half of the patients $(54.5 \%)$ who visit a retail clinic do not make any visits to their primary care physician, compared to only $31 \%$ for those who do not use a retail clinic, thus suggesting that retail clinics might undermine preventative care. ${ }^{37}$ Therefore, more research is needed to shed more light on whether retail clinics lead to care fragmentation.

\section{Patient satisfaction}

Patients in the USA are not satisfied with the traditional primary care system. One in four patients complains that they wait 30 minutes or longer in the exam room before being seen by the physician. Other complaints include not being able to schedule an appointment within 1 week, physicians spending too little time with patients, test results not provided in a timely manner, and physicians not responding to phone calls promptly. ${ }^{38}$ In contrast, patients are more satisfied with convenience, having qualified staff to provide care, cost of care, and quality of care in retail clinics. ${ }^{22,39,40}$ However, some concerns relating to feeling rushed and not feeling a connection with the provider are occasionally raised by retail clinic users.

\section{Costs of care and savings}

Retail clinics can provide care at lower costs because they use less-expensive providers, provide care in smaller settings, and specialize in low-acuity conditions. Episodes of care initiated at retail clinics cost $\$ 110$, compared with $\$ 166$ for those originating at physician offices, $\$ 156$ at urgent care clinics, and $\$ 570$ at hospital emergency rooms. ${ }^{13}$ Similarly, costs of care for visits at MinuteClinic versus other care settings showed that the average cost of retail clinic visit was \$51 less than in an urgent care center, \$55 less than in a physician office, and \$279 less than in a hospital emergency room. ${ }^{41}$ Approximately $13 \%-27 \%$ of hospital emergency room visits could take place at retail clinics (and urgent care centers), with potential annual savings of $\$ 4.4$ billion annually. ${ }^{32}$ Moreover, if flu shots administered in physician offices are administered in retail clinics instead, costs could be reduced to $\$ 2.4$ billion annually. ${ }^{16}$ The evidence is very clear that retail clinics provide services at a lower cost than other sites of care, with substantial savings for the health care system at large. Some experts have argued that retail clinics may lead to new utilization which leads to lower cost savings. However, even if retail clinics are inducing demand by bringing in nonusers to the health care system, there are long-term savings as these patients tend not to delay their care, get preventative services, and deal with minor problems before they become more serious and costlier.

\section{Innovation theory}

Given their recent growth and strategies of directly addressing problems surrounding care convenience, retail clinics constitute a form of innovation in health care. ${ }^{19,41}$ In this section, we review several theories and discuss their implications and limitations, especially within the context of health care reform legislation in the USA. Retail clinic growth, especially among health care systems, has coincided with the implementation of the Patient Protection and Affordable Care Act (ACA) (also known as health care reform or "Obama Care"). The Act, passed in 2010, includes major provisions affecting how health care organizations provide care and get rewarded or penalized for quality and cost outcomes (more explanation of the role played by the ACA in this trend is explained later).

\section{Diffusion of innovation theory}

An innovation is "an idea, practice, or project that is perceived as new by an individual or other unit of adoption". ${ }^{42}$ Since the publication of the Diffusion of Innovation Theory by Rogers in 1961, the study of innovations in organizations has intensified. ${ }^{42,43}$ Rogers describes diffusion as the "the process in which an innovation is communicated thorough certain channels over time among the members of a social system". ${ }^{42}$ He argues that organizations adopt innovations at different rates, and thus can fall into one of five adopter categories: innovators, early adopters, early majority, late majority, and laggards. For retail clinics, the innovators were the entrepreneurs and venture capitalists who first introduced the concept to retailers. Early adopters were the major retail and pharmacy chains (such as Target, Walmart, CVS, and Walgreens) that developed the innovations and helped spread them. The first hospital systems to develop or partner with a retail clinic prior to 2010 are the early majority, whereas those that waited till after the passage of the ACA represent the late majority and the laggards.

\section{Creative destruction theory}

Retail clinics can also be examined through the lens of creative destruction theory. ${ }^{44}$ Creative destruction refers to the constant process innovation mechanisms by which new ways to deliver products/services replace outdated ones. This process is characterized by countless decisions to create and destroy production arrangements and service delivery models. According to Schumpeter, 
[...] The fundamental impulse that sets and keeps the capitalist engine in motion comes from the new consumers' goods, the new methods of production or transportation, the new markets, the new forms of industrial organization that capitalist enterprise creates. ${ }^{44}$

Therefore, innovators and entrepreneurs introduce new products and services in order to generate profits. New models and new services compete with existing ones, taking customers by offering lower prices, better performance, new features, faster service, or more convenient locations in the marketplace. Unexpectedly, this pursuit of self-interest by innovators starts the progress that benefits everyone in the marketplace. Established companies survive by streamlining production with newer and better tools that boost employee productivity, whereas companies that no longer deliver what consumers want at competitive prices lose business, and eventually wither and die. Resources are shifted from declining sectors to more valuable ones, as companies seek their highest returns. The emergence of retail clinics represents an interesting example of gradual creative destruction in primary health care delivery. The entrepreneurs, retailers, and venture capitalists who introduced the clinics were originally driven by profit-maximization motives. However, by introducing an innovation model that provides services that are cheaper, faster, more convenient, and as effective as those provided in primary care physician offices, they helped generate a greater good to health care consumers. Some hospital systems saw the potential for improved delivery and revenue generation by developing or partnering with retail clinics. They made strategic decisions to streamline their existing services and integrate them with the destructive innovation.

\section{Disruptive innovation theory}

According to Christensen, ${ }^{45}$ there are two types of performance improvement trajectories for products and services: sustaining innovations and disruptive innovations. Sustaining innovations are products/services of the highest quality that are sold to the most sophisticated customers and are continually updated with enhanced features. But when such products/services overshoot customers' needs, disruptive innovations emerge. Initially, new disruptive products/ services do not appeal to many customers because they are perceived as inferior. Similarly, organizations offering disruptive innovations are rarely perceived as serious threats by dominant incumbents as they tend to be new entrants to the market. However, disruptive innovations typically start to attract new and less-demanding customers as they are cheaper, simpler, and more convenient. As their performance improves over time, they meet the needs of more customers, including those of the sustaining innovations. Eventually, the majority of the market prefers the disruptive innovation, while the sustaining one fails or ceases to exist. ${ }^{46,47}$

In health care, traditional delivery organizations such as hospitals and physician offices represent the predominant setting where highly skilled clinicians diagnose and treat complex problems using expensive technologies. However, with the introduction of retail clinics by retailers, investorowned companies, and entrepreneurs, these models have presented a disruptive innovation by using repetitive, valueadding processes to treat straightforward conditions in convenient and less-costly settings..$^{47}$ Initially, less demanding customers, including those lacking an established relationship with a health care provider, were attracted. But over time, more high-end customers that value easy access and convenience started using the clinics. Figure 1 depicts the gradual emergence of retail clinics as disruptive innovations that now challenge other traditional models of health care delivery. As discussed earlier, retail clinics are now viewed by some patients as a preferred alternative to meet their needs for minor conditions. However, despite retail clinics starting to disrupt some aspects of health care, they are still a long way from driving incumbent organizations out of business. The 1,900 retail clinics currently in operation represent only a small portion of primary care delivery, and although visits have reached $\sim 10$ million in 2014, they account for only $2 \%$ of primary care visits in the USA. ${ }^{24}$ Thus, somehow against the predictions of disruptive innovation theory, the incumbent health care organizations with sustaining innovations (ie, hospitals) have not been driven out by the disruptive innovations. Instead, this example of disruptive innovation seems to follow a slightly different path, as hospitals and health systems have recently joined the trend of partnering with or developing their own retail clinics, as mentioned before..$^{20,27-31}$

This is a remarkable development in the application of disruptive innovations to health care, as the very same organizations that rely on sustaining innovations and whose future viability may be threatened by retail clinics are now adopting these models as part of their strategies. Hwang and Christensen ${ }^{47}$ suggest that the only instance when an original market leader successfully transitions to becoming a leader in the new disruptive innovation occurs when the incumbent can successfully establish an entirely autonomous business unit organized around the disruptive value proposition. Moreover, the passage of the ACA, which introduced unique cost and quality challenges for provider organizations, represents another possible factor that may have accelerated the adoption 


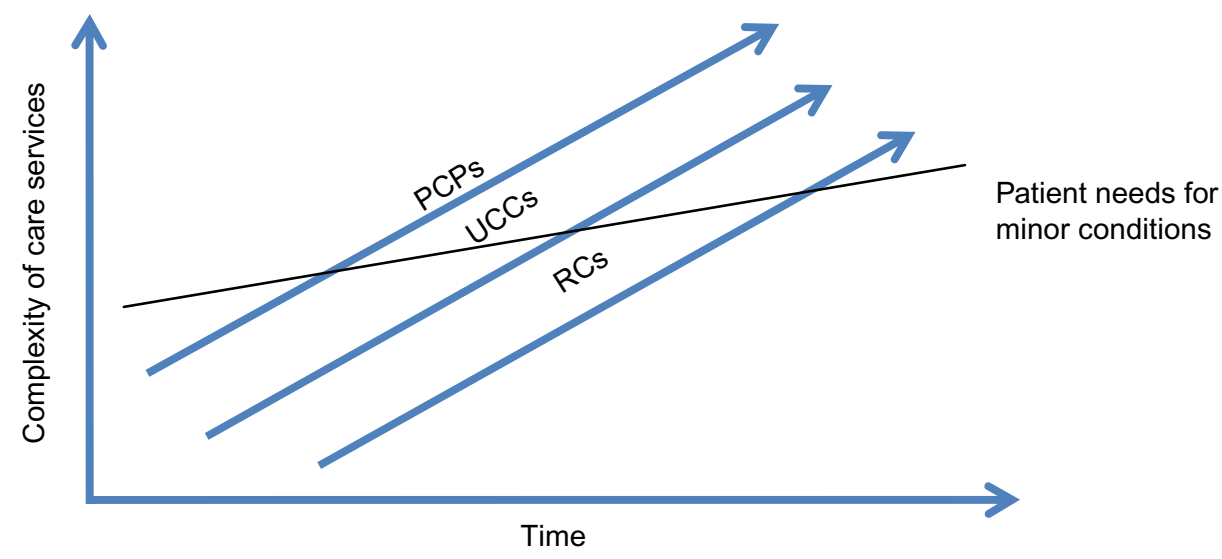

Figure I Convenient care services as disruptive innovations.

Abbreviations: PCPs, primary care physicians; RCs, retail clinics; UCCs, urgent care centers.

of retail clinics by hospital systems. The ACA requires hospital systems and other providers to have greater accountability and financial risk, while shifting their focus from treating individual patients in hospitals or physician offices to managing population health throughout the continuum of care. In addition, by providing insurance to an additional 32 million Americans by 2019 , the ACA has contributed to an unprecedented increase in demand for primary care and specialty services without a corresponding increase in provider supply. ${ }^{48}$ Thus, these important legislative changes have prompted hospitals and health systems to change their organizational practices and operations, as well as to design and embrace efficient and inventive strategies for delivering care, such as retail clinics.

\section{Future of retail clinics}

Despite the remarkable growth in retail clinics, many questions remain about their potential and future viability in the health care system at large. Forecasts suggest that the Compound Annual Growth Rate (which is the year-over-year growth rate of an investment over a specified period of time) for retail clinics for the period 2011-2018 will be 11.2\% and that the number of clinics is expected to reach 2,854 by $2018 .^{49}$

\section{Expansion of scope}

The business model for retail clinics consists of a nurse practitioner or physician assistant who handles a basic menu of preventative and easy-to-diagnose routine conditions. In the last few years, there have been many signs that clinic operators are seeking to change the model by expanding the scope of services offered. These strategies have severely angered various physician groups.

Proponents for expansion argue that many patients do not normally adhere to their physician recommendations and do not visit their offices regularly because of lack of convenience. Therefore, allowing patient monitoring on a convenient walkin basis can lead to improved access and better outcomes. Moreover, nurse practitioners are well equipped to provide these services, as many of them already manage patients' chronic diseases in physician offices. However, the potential for care fragmentation is very significant. For example, monitoring of blood pressure, cholesterol, or blood sugar may be done at the retail clinic, but patients may need medication adjustments or further counseling from their physician. The results of the tests performed at a retail clinic may not be communicated to the primary care office. Moreover, examining chronic conditions in retail clinics may result in missed opportunities to identify related problems that would normally be addressed in a broader-scope primary care visit. ${ }^{32}$

Nonetheless, expansion of scope strategies has been pursued by several retail clinic operators in the last few years. H-E-B RediClinic launched Weigh Forward, a comprehensive, medically supervised weight management program, whereas CVS/MinuteClinic developed a diabetes management program focusing on biometric screenings such as glucose, hemoglobin Alc, blood pressure, weight, and foot exams, as well as weight management counseling programs and asthma maintenance therapy education. Similarly, Walgreens Take Care Clinics established assessment, treatment, and management for hypertension, diabetes, high cholesterol, and asthma. ${ }^{24}$

\section{Conclusion}

Retail clinics appear to be at a transition point as an innovative model of health care delivery.

The challenges that were originally faced by the industry, such as contracts with insurance companies, opposi- 
tion from the medical community, and consumer attitudes, seem to have eased. The basic value proposition of convenience, affordability, and quality is now more accepted by consumers and providers. However, serious questions remain: What role will hospitals systems continue to play? How to increase patient utilization in order to establish a sustainable business model? Does expansion into chronic disease management represent a successful strategy for the long-term?

\section{Disclosure}

The author reports no conflicts of interest in this work.

\section{References}

1. Bohmer RMJ, Groberg JP. QuickMedx Inc. Harvard Business School Case. 603-049. 2002, July. (Revised April 2003).

2. Martin E. QuickMedx preps to take clinic concept national; 2003. Available from: www.Upsizemag.com. Accessed October 15, 2015.

3. MinuteClinic; 2015. Available from: http://www.minuteclinic.com/. Accessed October 15, 2015.

4. Taylor H. Innovations in care delivery: Retail clinics. Retail clinics: A new trend in health care. Presented at: A National Consumers League Stakeholders Forum, September 18, 2008; Washington, DC.

5. Kaissi A, Charland T. The evolution of retail clinics in the United States, 2006-2012. Health Care Manag. 2013;32(4):336-342.

6. CCAClinics.org. Convenient Care Association. Available from: http:// www.ccaclinics.org/index.php?option $=$ com_content\&view $=$ article $\&$ i $\mathrm{d}=4 \&$ Itemid $=116$. Accessed October 15, 2015.

7. PwC. Medical Cost Trend: Behind the Numbers 2014. Health Research Institute; 2013.

8. Rudavsky R, Mehrotra A. Sociodemographic characteristics of communities served by retail clinics. J Am Board Fam Med. 2010;23(1):42-48.

9. Scott MK. Health Care in the Express Lane: The Emergence of Retail Clinics. California: HealthCare Foundation; 2006.

10. Hansen-Turton T, Ryan S, Miller K, Counts M, Nash D. Convenient care clinics: the future of accessible health care. Dis Manag. 2007;10(7):61-73.

11. Scott MK. Building and marketing a retail clinic. In: Riff J, Ryan SF, Hansen-Turton T, Editors. Convenient Care Clinics. New York: Springer Publishing Company; 2013:161-170.

12. Ashwood JS, Reid RO, Setodji CM, Weber E, Gaynor M, Mehtrotra A. Trends in retail clinic use among the commercially insured. Am J Manag Care. 2011;17(11):e443-e448.

13. Mehrotra A, Wang MC, Lave JR, Adams JL, McGlynn EA. Retail clinics, primary care physicians, and emergency departments: A comparison of patients' visits. Health Aff. 2008;27(5):1272-1282.

14. Uscher-Pines L, Harris KM, Burns R, Mehrotra A. The growth of retail clinics in vaccination delivery in the U.S. Am J Prev Med. 2012;43(1): $63-66$.

15. Eder R. A crowded market emerges to fill growth prescription. $D S N$. Available from: http://business.highbeam.com/413375/article1G1-135665176/crowded-market-emerges-fill-growth-prescription. Accessed October 15, 2015.

16. Grossman E. Retail clinics: what the data shows. Paper presented at: Retail Clinician Education Congress; 2013; New York, NY.

17. Callahan, E. Retail clinics can be a valuable source partner. Medical Staff Briefing. 2007;17:8.

18. Boehringer Ingelheim Pharmaceuticals, Inc. Boehringer Ingelheim Pharmacy Satisfaction ${ }^{\mathrm{TM}}$ : Retail Clinic Outlook; 2010. Available from: http://www.pharmacysatisfaction.com/resources/pdf/MI73586TRF_ RCO_Appendix.pdf. Accessed October 4, 2015.
19. Malvey DM, Fottler MD. The retail revolution in health care: Who will win and who will lose? Health Care Manage Rev. 2006;31(3): $168-178$.

20. Fottler M, Malvey D. The Retail Revolution in Health Care. Santa Barbara: Praeger; 2010.

21. Tu Ha T, Cohen GR. Checking up on retail-based health clinics: Is the boom ending? Issue Brief (Commonw Fund). 2008;48:1-11.

22. Wang MC, Ryan G, McGlynn EA, Mehrotra A. Why do patients seek care at retail clinics and what alternatives did they consider. Am J Med Qual. 2010;25(2):128-134.

23. Richman D. Harris interactive: Consumer trends in retail medicine. Paper presented at: Retail clinician education congress; 2013; New York, NY.

24. Bachrach D, Frohlich J, Garcimonde A, Nevitt K. Building a culture of health: The value proposition of retail clinics; 2007. Available from: http://www.rwjf.org/content/dam/farm/reports/issue_briefs/2015/ rwjf419415. Accessed October 4, 2015.

25. Laws M, Scott MK. The emergence of retail-based clinics in the United States: early observations. Health Aff. 2008;27(95):1293-1298.

26. Tu HT, Boukus ER. Despite Rapid Growth, Retail Clinic Use Remains Modest (Research Brief 29). Washington, DC: Center for Studying Health System Change; 2013.

27. Fenn S. Integrating retail clinics into the hospital system. Front Health Serv Manag. 2008;24(3):33-36.

28. Kaissi A. Hospital- affiliated and hospital-owned retail clinics: Strategic considerations and operational challenges. J Healthc Manag. 2010;55(5):325-329.

29. Lin DQ. Convenient care clinics: opposition, opportunity, and the path to system integration. Front Health Serv Manag. 2008;24(3):3-11.

30. Newbold P, O'Neil MJ. Small changes lead to large effects. Front Health Serv Manag. 2008;24(3):23-27.

31. Pollert P, Dobberstein D, Wiisanen R. Jumping into the healthcare market: Our experience. Front Health Serv Manag. 2008;24(3):13-21.

32. Weinick RM, Pollack CE, Fisher MP, Gillen EM, Mehrotra A. Policy implications of the use of retail clinics. Rand Health Technical Report. Arlington: RAND Corporation; 2010.

33. Woodburn JD, Smith KL, Nelson GD. Quality of care in the retail health care setting using national clinical guidelines for acute pharyngitis. Am J Med Qual. 2007;22(6):457-462.

34. Shrank WH, Krumme AA, Tong AY, et al. Quality of care at retail clinics for 3 common conditions. Am J Manag Care. 2014;20(10):794-801.

35. Mehrotra A, Gidengil A, Setodji CM, Burns RM, Linder JA. Antibiotic prescribing for respiratory infections at retail clinics, physician practices, and emergency departments. Am J Manag Care. 2015;21(4): 294-302.

36. Reid RO, Ashwood JS, Friedberg MW, Weber ES, Setodji CM, Mehrotra A. Retail clinic visits and receipt of primary care. J Gen Intern Med. 2008;28(4):504-512.

37. Rohrer JE, Yapuncich KM, Adamson SC, Angstam KB. Do retail clinics increase early return visits for pediatric clinics? J Am Board Fam Med. 2008;21:475-476.

38. Hitti M. Waiting room tops patient complaints: Patients generally satisfied with doctor-patient relationship, but both sides have gripes; 2007. Available from: www.webmd.com/health-insurance/20070108/ waiting-room-tops-patient-complaints. Accessed October 4, 2015.

39. Harris Interactive Online Onsite Health Clinic Bulletin Board; June 2007. Available from: http://www.amcp.org/WorkArea/DownloadAsset. aspx?id=11981

40. Hunter LP, Weber CE, Morreale AP, Wall JH. Patient satisfaction with retail health clinic care. $J$ Am Assoc Nurse Pract. 2009;21(10): 565-570.

41. Thygeson M, Van Vorst KA, Maciosek MV, Solberg L. Use and costs of care in retail clinics versus traditional care sites. Health Aff. 2008;5:1283-1292.

42. Rogers EM. Diffusion of Innovations. 5th ed. New York: Simon and Schuster; 2003. 
43. Rogers EM. Diffusion of Innovations. New York: Simon and Schuster; 1962.

44. Schumpeter J. Capitalism, Socialism, and Democracy. 3rd ed. New York: Harper and Brothers; 1942.

45. Christensen C. The Innovator's Dilemma: When New Technologies Cause Great Firms to Fail. Boston: Harvard Business School Press; 1997.

46. Christensen CM, Bohmer R, Kenagy J. Will disruptive innovations cure health care? Harv Bus Rev. 2000; 78(5):102-117.
47. Hwang J, Christensen CM. Disruptive innovation in health care delivery: A framework for business-model innovation. Health Aff. 2008 27:1329-1335.

48. Auerbach DI, Chen PG, Friedberg MW, et al. Nurse-managed health centers and patient-centered medical homes could mitigate expected primary care physician shortage. Health Aff. 2013;32:1933-1941.

49. GBI Research. Retail Clinics - 2012 Yearbook. GBI Research; 2012.

\section{Publish your work in this journal}

Innovation and Entrepreneurship in Health is an international, peer reviewed, open access journal publishing original research, reports, reviews and commentaries on innovation and entrepreneurship in health. Special focus will be given to the theory, process, and practice of innovation and entrepreneurship by individuals and organizations

\section{Dovepress}

within the health care context globally. The manuscript management system is completely online and includes a very quick and fair peer review system, which is all easy to use. Visit http://www.dovepress.com/ testimonials.php to read real quotes from published authors.

Submit your manuscript here: http://www.dovepress.com/innovation-and-entrepreneurship-in-health-journal 